\title{
PSEUDOFULGURITA EL ROSARIO: UN AGREGADO VÍTREO EXÓTICO EN EL ESTADO DE HIDALGO
}

\author{
Luis Enrique Ortiz Hernández ${ }^{1-2}$ e Israel Hernández Pérez ${ }^{3}$ \\ ${ }^{1}$ Consejo de Recursos Minerales, Gerencia de Investigación Aplicada. \\ Blv. Felipe Ángeles $s / n$ km 93.5 Col. Venta Priet, C.P. 42080, Pachuca, Hgo. \\ ${ }^{2}$ Sección de Estudios de Posgrado e Investigación IPN, ESIA-Unidad Zacatenco. \\ Ed. No. 12, 3er. Piso, Apdo. Postal 75-136, México, D.F. \\ ${ }^{3}$ Consejo de Recursos Minerales, Gerencia de Geofisica. Blv. Felipe Ángeles \\ $s / \mathrm{km} 93.5$ Col Venta Prieta, C.P. 42080, Pachuca, Hgo.
}

\section{RESUMEN}

\begin{abstract}
Varios fragmentos de pseudofulgurita, siendo el mayor denominado El Rosario de $6.475 \mathrm{~kg}_{\text {, }}$ encontrados el día 21 de Mayo de 1995, en el Ejido El Rosario, cerca de Tepatepec, estado de Hidalgo. El sitio del hallazgo es un terreno de cultivo ubicado en las coordenadas geográficas $99^{\circ} 05^{\prime}$ de latitud norte y $20^{\circ} 15^{\circ}$ de longitud oeste. Megascópicamente el fragmento estudiado tiene un aspecto vítreo de color verde olivo y brillo resinoso con abundantes oquedades y escasas esferas metálicas gris acero, rodeado por una coraza gris negruzca de aspecto escoriáceo, parcialmente brechada y conteniendo estructuras tubulosas.

El peso especifico promedio del agredado vítreo es de 2.548 . Su análisis mineralógico muestra que la parte vitrea está formada de un vidrio silicoaluminoso ( $)$ 1.537), con estructura brechoide, conteniendo esferas metálicas de silícidos y microcristales subedrales de clinopiroxeno. En la parte escoriácea que recubre la parte vítrea se identificó a polimorfos de la silice (cuarzo, tridimita, cristobalisa) y plagioclasa, así como impregnaciones de portlandita, calcita e hidróxidos de calcio.

Los análisis químicos de roca total muestran un enriquecimiento en componentes refractarios tales como $\mathrm{SiO}_{2}$ y $\mathrm{Al}_{2} \mathrm{O}_{3}$ y valores menos importantes de $\mathrm{Na}_{2} \mathrm{O}, \mathrm{K}_{2} \mathrm{O}_{1}, \mathrm{CaO}$, $\mathrm{FeO}$ y $\mathrm{TiO}_{2}$, que representa la composición química del material arcilloso y limoso del suelo a partir del cual se formó la pseudofulgurita. La evidencia muestra que el origen de ésta se debió a la descarga eléctrica producida por la ruptura de una línea de alta tensión (13,000 volts) que impactó la superficie del terreno de cultivo.

Palabras clave: Pseudofulgurita, caracterización mineralógica, composictón quimica, estado de Hidalgo, México.
\end{abstract}

\section{ABSTRACT}

EI Rosario pseudofulgurita $(6.475 \mathrm{~kg})$ an other small vitreous fragments, were recovered May 21 st, 1995 , in Ejido El Rosario, near Tepatepec, Hidalgo state $\left(99^{\circ} 05^{\prime} \mathrm{N}\right.$ and $20^{\circ} 15^{\prime} \mathrm{S}$ ). A brecciated and tubular structure formed by a green siliceous and aliminous glass with $n>1.537$ and a specific gravity of 2.548 are the characteristics of the biggest fragment. It include gray metalic spheres of silicides, and rare clinopyroxene microcrysts. In the scoriaceous part surrounding the glass, were identified silica polymorphs (quart, tridimite and cristobalite), plagioclase, portlandite, calcite and calcic hydroxides.

Whole-rock analysis of both glassy and scoriaceous phases show $\mathrm{Sio}_{2}$ and $\mathrm{Al}_{2} \mathrm{O}_{3}$ enrichment, and $\mathrm{Na}_{2} \mathrm{O}$, $\mathrm{Ko}, \mathrm{CaO}, \mathrm{FeO}^{*}$ and $\mathrm{TiO}_{2}$ contents that represent the whole chemical composition of the argillaceous and silty precursor soil. El Rosario pseudofulgurite was produced when a broken high-power line (13,000 volts) fell to the ground.

Key Words: Pseudofulgurte, mineralogical characterization, chemical composition, Hidalgo state, Mexico.

\section{INIRODUCCIÓN}

Un agregado vítreo de $6.475 \mathrm{~kg}$ asi como otros fragmentos pequeños vítreos y escoriáceos fueron recuperados el día 25 de Mayo de 1995, en el Ejido El Rosario, Mpio. de Francisco I. Madero, localizado aproximadamente $8 \mathrm{kms}$ al oriente de Tepatepec, en el estado de Hidalgo. El agregado vítreo, que fue considerado por los habitantes del lugar como un fragmento de meteorito, contrasta notablemente con las formaciones geológicas circundantes constituidas por suelos arcillosos y limosos derivados de la meteorización de tobas ácidas y tobas carbonatadas, por lo que su origen se considera exótico. El sitio del hallazgo fue un terreno de cultivo, propiedad del señor Tomás Zamora Pérez, ubicado en las coordenadas geográticas $99^{\circ} 05^{\prime}$ de latitud norte y $20^{\circ}$ $15^{\prime}$ de longitud oeste (Fig. 1). 


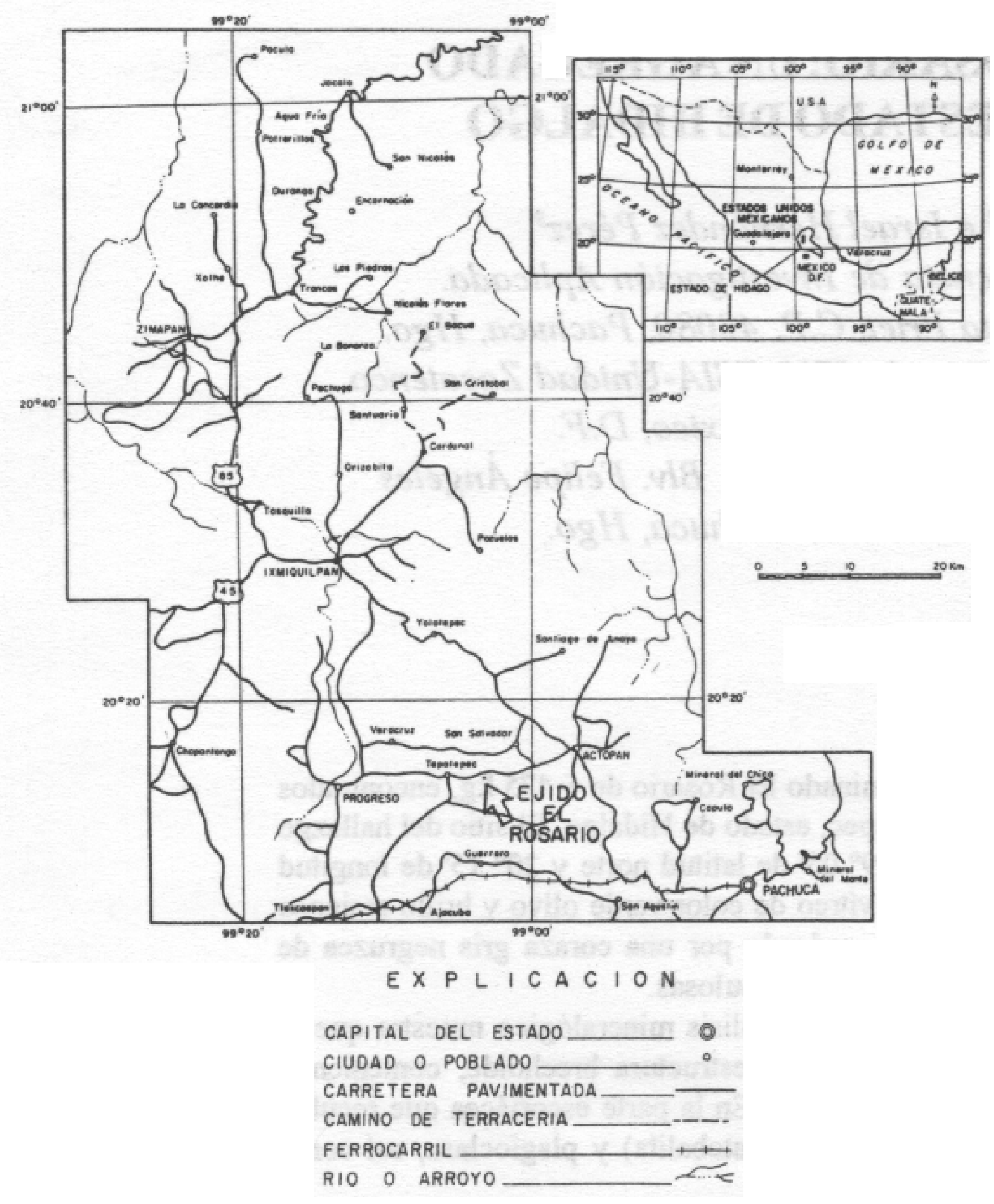

Figura 1.- Mapa de Localización Geográfica mostrando donde se encontró el fragmento Vitreo.

Los autores del presente trabajo acudieron en compañía de funcionarios municipales de Tepatepec y del Ing. Francisco Quijas Cruz, miembro de la Dirección General de Protección Civil del Estado de Hidalgo, ya que los habitantes de El Rosario solicitaron apoyo para detectar posible radiactividad en la zona del supuesto impacto del meteorito. Con objeto de tranquilizar a éstos, se procedió a medir ésta con un espectrómetro de rayos gamma SCINTREX GIS-4, obteniéndose mediciones del orden de $60-80$ cuentas por segundo (cps) de cuenta total, lo que es una medida del valor de fondo delmaterial que conforma el terreno (arcillas y limo).

Relata el señor Alfredo Zamora Vázquez, comisariado ejidal de El Rosario, que el día domingo 21 de Mayo, entre las 19:30 a 20:00 horas se encontraba en las afueras de su domicilio en compañía del señor Tomás Zamora Pérez, cuando de repente se percataron que en el sembradío de chiles propiedad de este último, los cables de alta tensión $(13,000$ volts) que cruzan éste habían sido rotos. $\mathrm{Al}$ acercarse al lugar, se percataron que un objeto incandescente yacía semienterrado en la tierra de cultivo, en una cavidad de forma ovalada de 80 X $60 \mathrm{~cm}$ y $10 \mathrm{~cm}$ de profundidad. Al otro día volvieron al sitio pero no pudieron desenterrar el objeto ya que estaba aún caliente, lo que se extendió al segundo día.
No fue sino hasta que los empleados de la Comisión Federal de Electricidad fueron a reparar los cables de alta tensión, el miércoles 24 , que desenterraron el supuesto meteorito y lo transladaron a sus instalaciones en la ciudad de Tepatepec. Acto seguido, el señor Alfredo Zamora Vázquez recuperó al otro día el fragmento vítreo, a instancias del ciudadano Presidente Municipal de Tepatepec, Lic. Francisco Morelos Fernández, quien se comunicó a la Dirección General de Protección Civil, en Pachuca, procediendo esta última a solicitar apoyo al Consejo de Recursos Minerales en lo tocante a transporte, medición de radiactividad y clasificación y análisis del agregado vítreo.

Los resultados obtenidos en la caracterización mineralógica y química de este agregado vítreo, así como la discusión acerca de su origen, constituyen el objetivo principal de este trabajo.

\section{DESCRIPCIÓN MEGASCÓPICA}

$\mathrm{El}$ fragmento vítreo mayor tiene una forma elipsoidal y en parte cilíndrica, con longitud aproximada de $35 \mathrm{cms}$, un aspecto vítreo de color verde olivo y brillo resinoso, rodeado por una coraza (2 a $3 \mathrm{cms}$ de espesor), gris negruzca de aspecto escoriáceo, parcialmente brechada y conteniendo estructuras tubulosas (Fig. 2). La parte vítrea presenta abundantes oquedades parecidas a vesículas en forma de gota de tamaño variable $(0.5-3 \mathrm{cms})$, en ocasiones intecomunicadas por medio de canales y escasas esferas metálicas gris acero de $1 \mathrm{~cm}$ hasta $3 \mathrm{~cm}$ de diámetro se

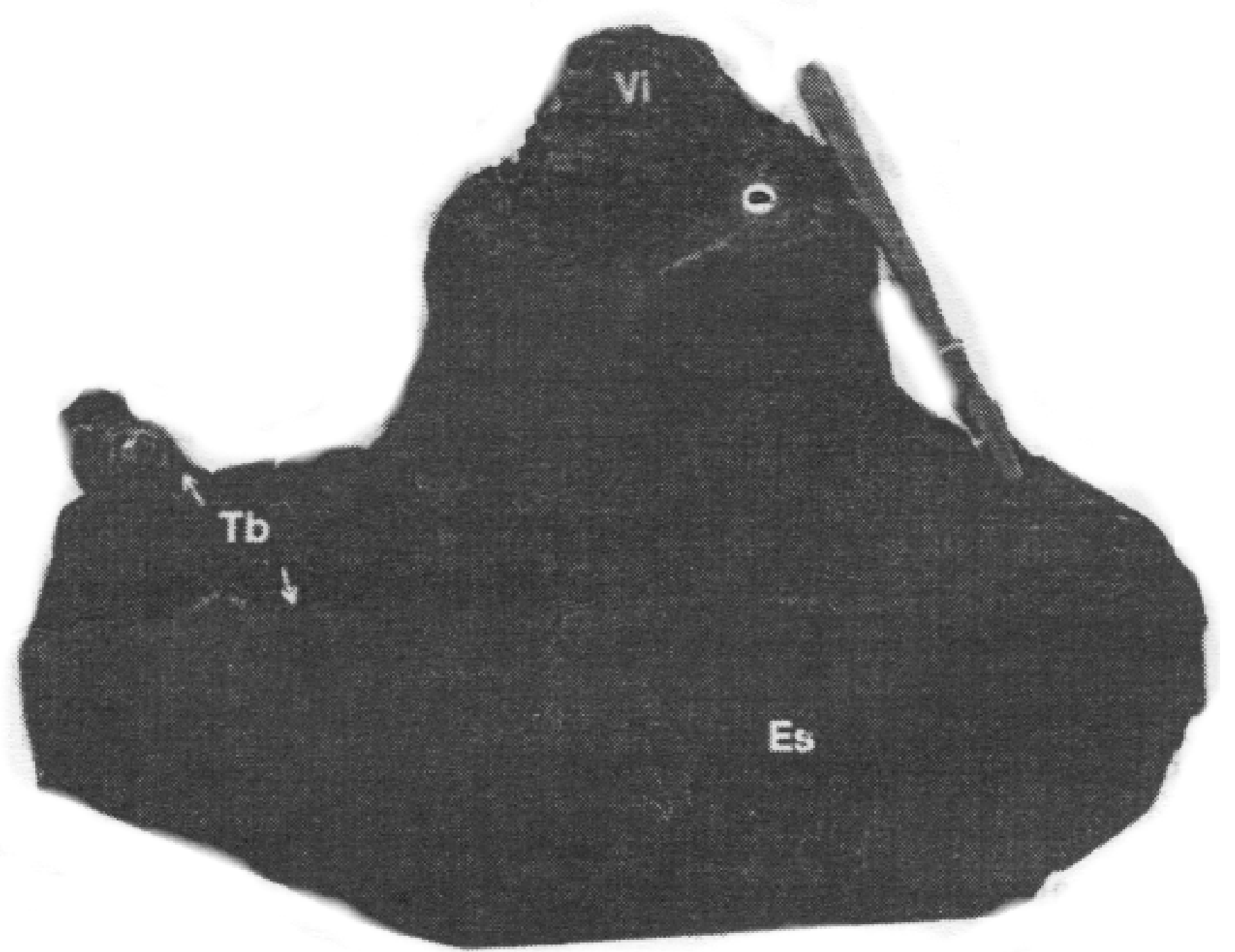

Figura 2.- Aspecto general de la pseudofulgurita mostrando las vesiculas en la parte vitrea ( $\mathrm{V}$ i), la coraza escoriácea brechoide (Es) que la recubre y las estructuras tubulosas (Tb). 
observan diseminadas (Fig. 3). En la coraza gris negruzca se reconoció también escasas impregnaciones de un material de color blanco mate.

Otros fragmentos pequeños vítreos de color verde y escoriáceos de color gris negruzco, semejantes a las estruc-

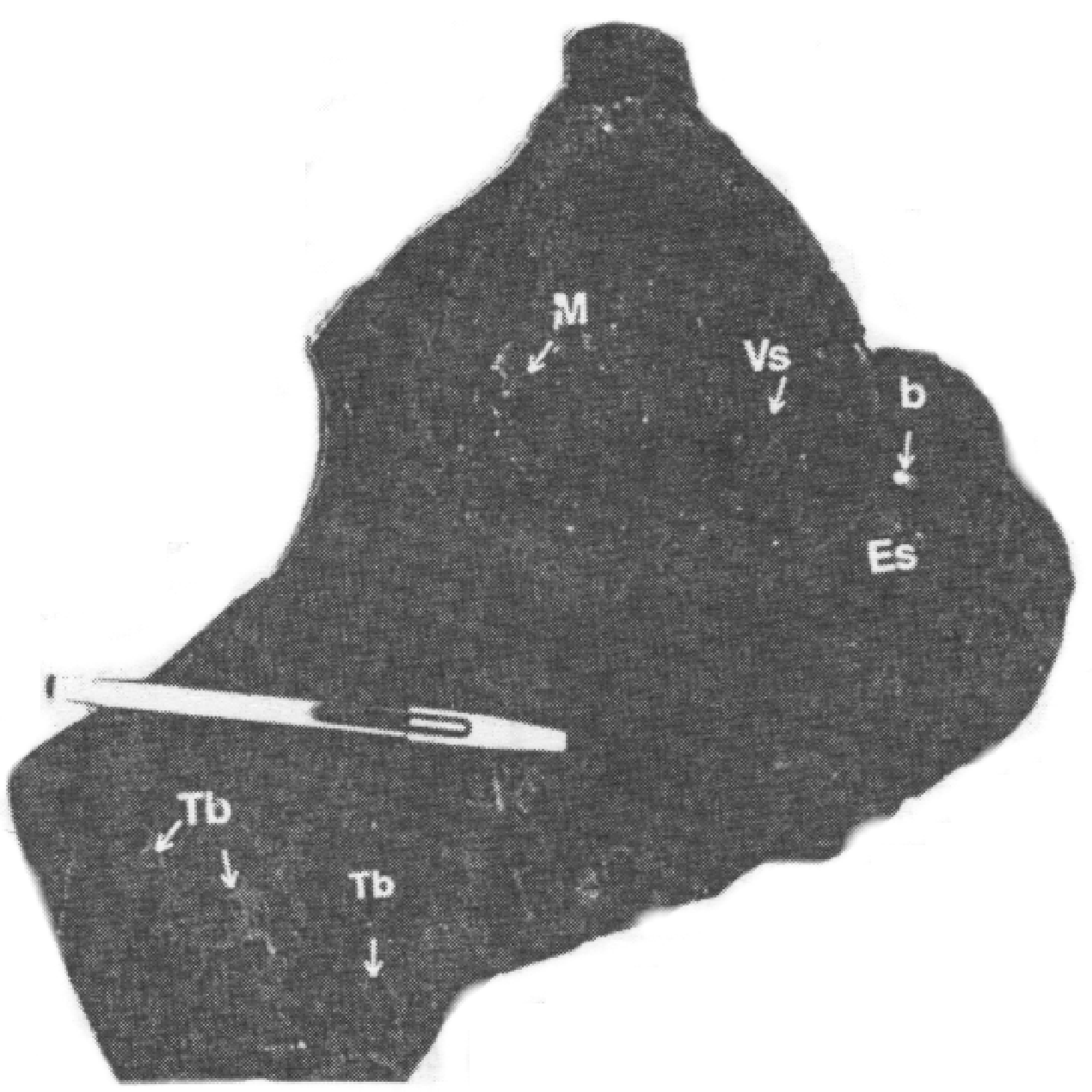

Figura 3. - Abundantes vesiculas (Vs) y una esfera metálica (M) en la parte vitrea de la pseudofulgurita. Se observa también la coraza escoriácea brechoide (Es) con una impregnación blanca (b) y las estructuras tubulosas.

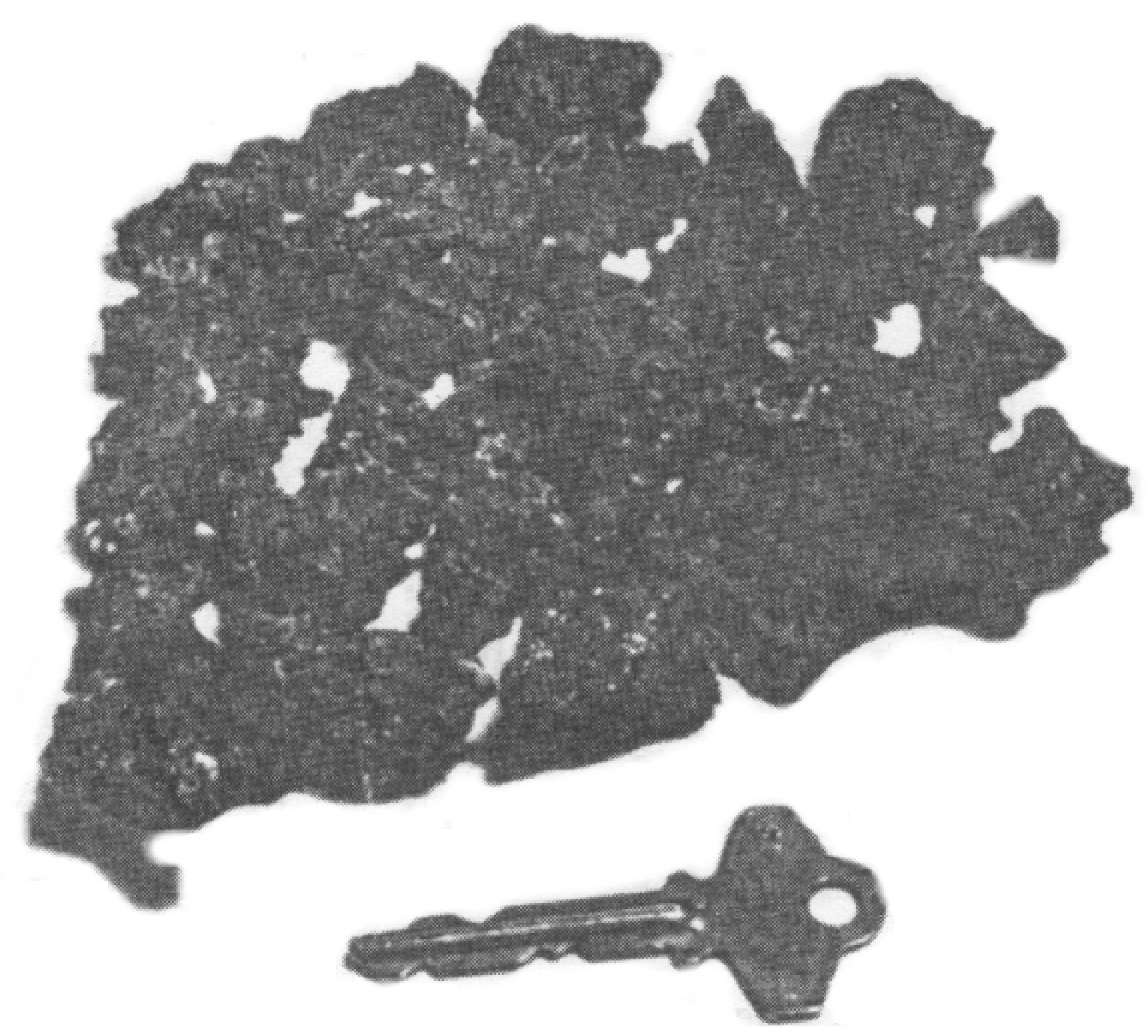

Figura 4. Fragmentos vitreos de tamaño pequeño que se encontraron esparcidos en el terreno de cultivo. Nótese su aspecto escoriáceo y su abundancia de vesiculas. turas tubulosas del fragmento mayor y de la misma composición también fueron encontrados esparcidos en el terreno de cultivo (Figs. 4 y 5 ).

\section{MÉTODOS ANALÍTICOS UTILIZADOS}

Los análisis necesarios para caracterizar química y mineralógicamente el agregado vítreo fueron desarrollados en el Centro Experimental Tecamachalco del Consejo de Recursos Minerales, en la ciudad de México.

Después de efectuar cortes de la parte vítrea, escoriácea derayos $\mathrm{X}$, con el objeto de identificar las fases mineralógicas presentes. Las muestras fueron analizadas empleando los tubos de cromo y tungsteno, en un difractómetro de rayos $\mathrm{X}$ marca RIGAKU. Acto seguido, se envió otra parte vítrea y otra escoriácea para su análisis de roca total mediante fluorescencia de rayos X, utilizándose un espectro-fotómetro de fluorescencia de rayos X marca RIGAKU DENKI. También se realizó la medición del peso específico de la muestra mediante picnómetro al alcohol 150-propílico a temperatura ambiente $\left(24^{\circ} \mathrm{C}\right)$ y se estudiaron tres láminas delgadas al microscopio petrográfico. Dos superficies pulidas fueron preparadaspara el estudio de la partemetálica a la microsonda electrónica (marca JEOL-JSM-35C) en el Instituto de Geología de la UNAM. Las condiciones analíticas utilizadas para los análisis cuantitativos a la microsonda electrónica fueron $15 \mathrm{kV}$ de potencial de aceleración y $100 \eta \mathrm{A}$ de intensidad de corriente. Los análisis obtenidos en porcentaje en peso fueron recalculados a $100 \%$ con el programa de corrección $\mathrm{ZAF}$ (número atómico, absorción y fluorescencia).

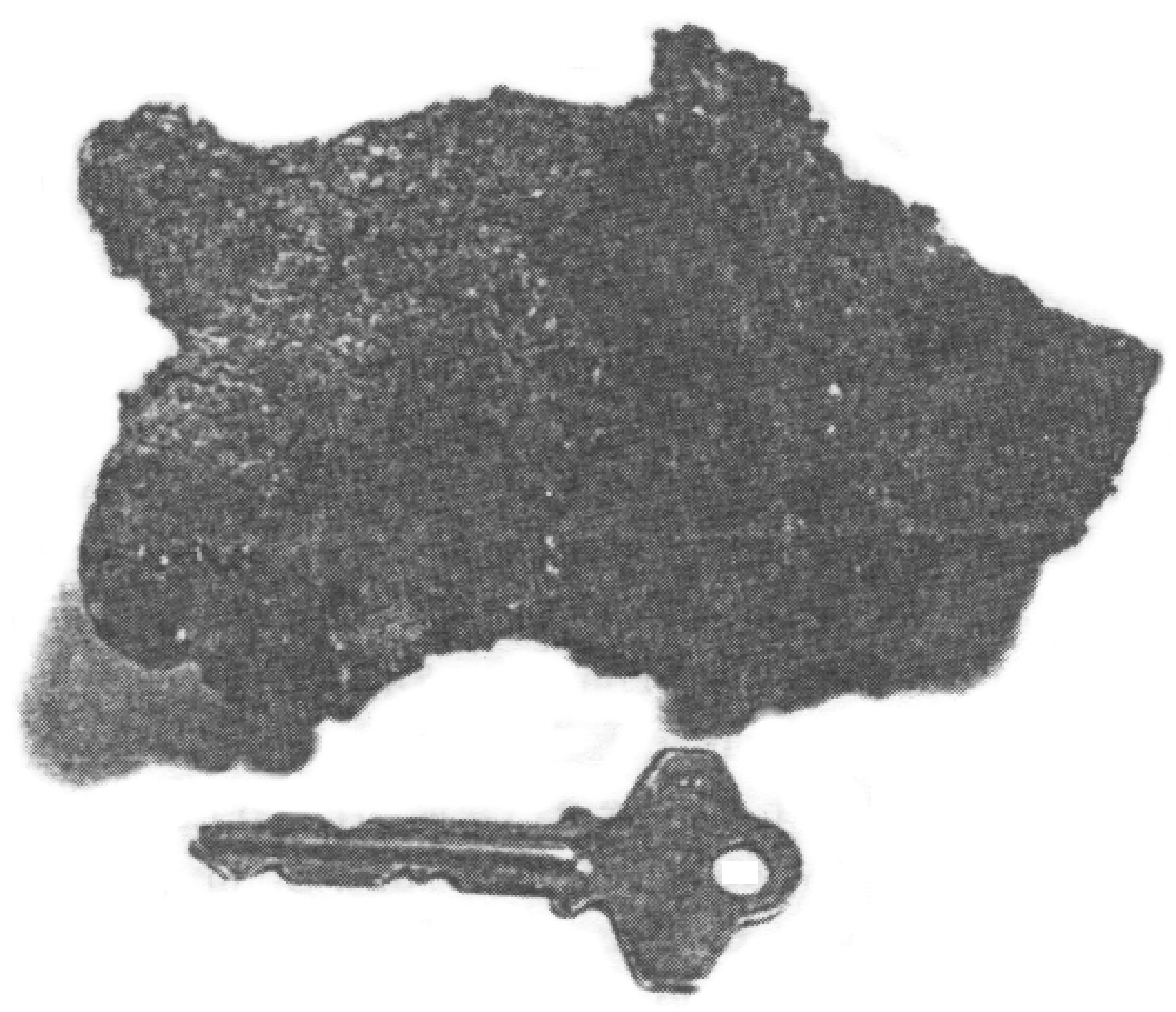

Figura 5. Uno de los fragmentos vitreos de mayor tamaño, de aspecto escoriáceo y brechamiento caracteristico. 


\section{RESULTADOS OBTENIDOS}

Dos mediciones del peso especifico de la parte vitrea arrojan valores de 2.488 y 2.608 , con un peso específico promedio de 2.548. Este peso especifico medio es similar a la densidad media reportada para calizas y dolomitas secas $\left(2.54 \mathrm{gr} / \mathrm{cm}^{3}\right)$ y es mayor al de fulguritas descritas en la literatura (p.e $=2.20$; Frondel, 1962).

Al microscopio de luz transmitida se observa un material incoloro isotrópico, en ocasiones con tonalidades verdosas, el cual se identificó como un vidrio de composición sílicoaluminoso ( $n$, bálsamo , 1.537). Este vidrio está rellenado en sus partes brechoides por hematita e hidróxidos de fierro, presentando abundantes oquedades y burbujas redondeadas, exsoluciones vermiformes con extinción ondulante de plagioclasay tridimita, asi como raras diseminaciones de microcristales subedrales de clinopiroxeno y esferas con lustre metálico. Dada la rareza y el tamaño tan pequeño de los microcristales de clinopiroxeno ( $5 \mathrm{~mm}$,) no fue posible determinar su composición exacta.

Por no tener una estructura atómica bien definida, mediante difracción de rayos $\mathrm{X}$ no pudieron determinarse los componentes de la parte vitrea, la cual forma un $87 \%$ modal de lamuestra. En la parteescoriácea se encontraronpolimorfos de la sílice (cuarzo, tridimita y cristobalita), así como plagioclasa (Fig. 6), mientras que en las impregnaciones blancas se reconoció la presencia de calcita, portlandita, óxido de calcio y feldespatos (Fig. 7). El análisis por difracción de rayos $\mathrm{X}$ de las esferas metálicas incluidas en el vidrio indica que se trata de una aleación refractaria de $\mathrm{Fe}$ y Si acompañada de hematita.

Los constituyentes del agregado vítreo en porcentaje modal se muestran en la Tabla 1. Ellos son reportados subdividiéndolos en parte vítrea, escoriácea e impregnaciones blancas.

Quimicamente, en la parte vitrea (muestra MET-1A) y escoriácea (muestra MET-1B) del agregado vitreo se constatan contenidos en elementos mayores casi similares, con la excepción del $\mathrm{FeO}$ que presenta un contenido mayor en la parte escroriácea, posiblemente debido a condiciones más oxidantes que prevalecieron en esta parte durante la formación del agregado vítreo (Tabla 2). Este agregado está casi en su totalidad 'vrmado de $\mathrm{SiO}_{2}, \mathrm{Al}_{2} \mathrm{O}_{3}$ y FeO*, ya que la suma de estos óx dos varia entre 90 y $88 \%$ en la parte vitrea y escoriácea respectivamente. La relación $\mathrm{Na} / \mathrm{Al}$ de ambas partes es inferior a 1, lo que es característico de mezclas sílicoaluminosas y vidrios (Mysen, 1988). Comparado con fulguritas reportadas en Australia (Frondel, 1962) y en Michigan, Estados Unidos (Essene y Fisher, 1986), la pseudofulgurita El Rosario es menos rica en silice pero más rica en alúmina, fierro total y álcalis
Los resultados del análisis normativo $\mathrm{CIPW}$ de las muestras analizadas indican que tanto la parte vitrea como la escoriácea son sobresaturadas en silice, lo que hace aparecer cuarzo libre en la norma. También la presencia de corindón normativo corrobora el carácter hiperaluminoso del agregado vítreo. Otros minerales normativos son albita, anortita y ortoclasa, que reflejan los contenidos en $\mathrm{Na}_{2} \mathrm{O}$,
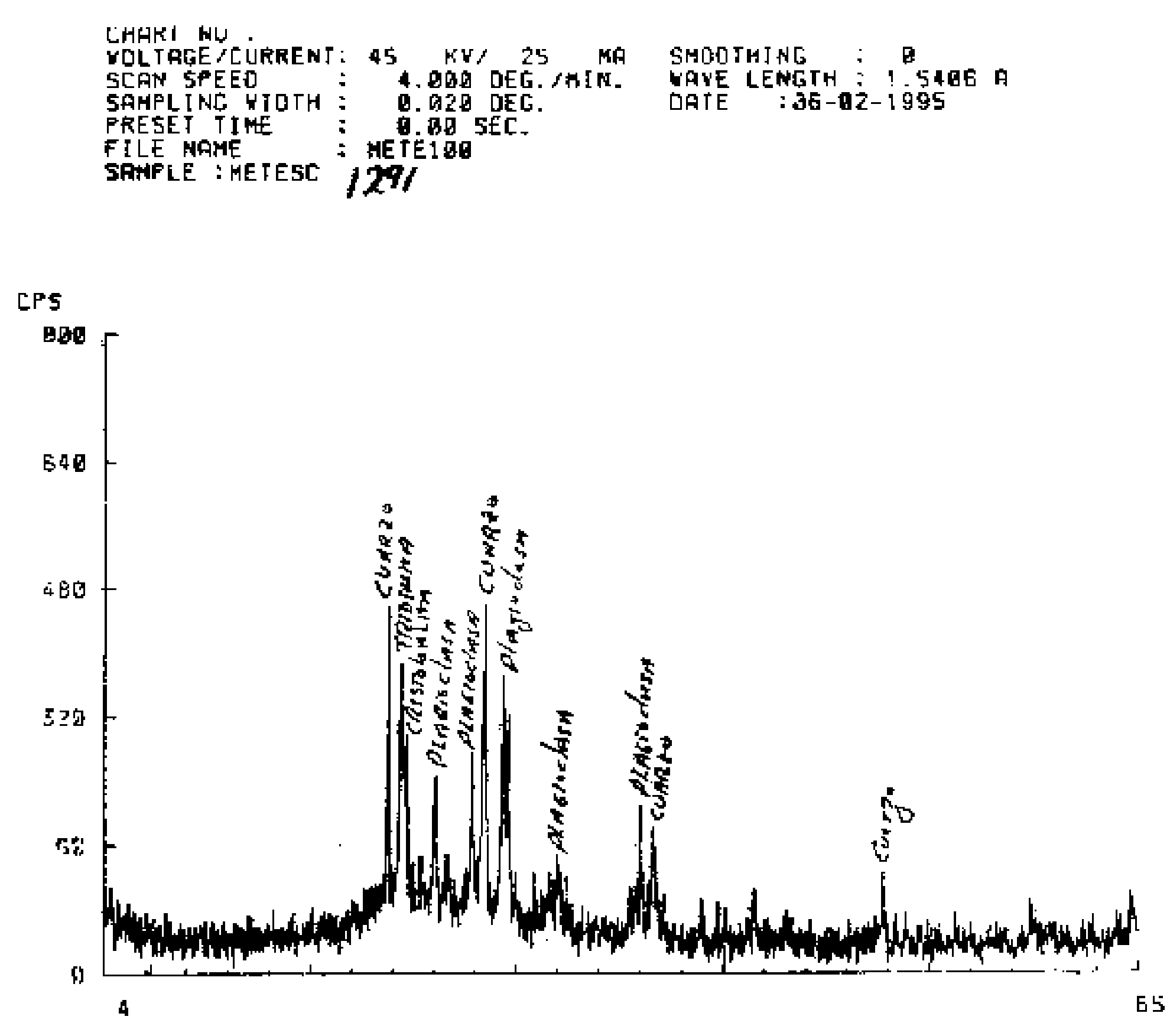

Figura 6. Diafractograma correspondiente a la parte escoriácea mostrando la presencia de polimorfos de la silice y piagnoclasa.

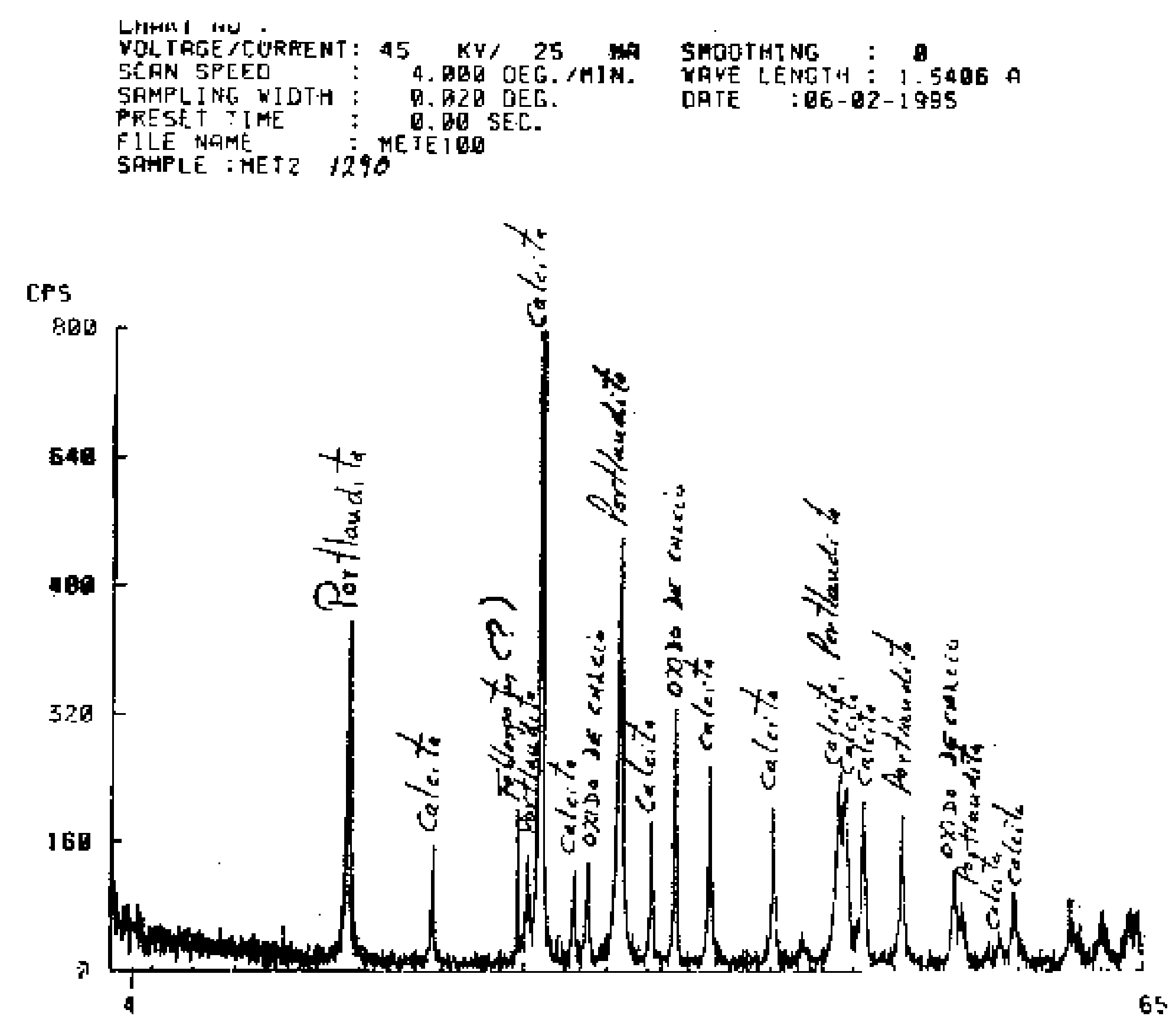

Figura 7. Diafractograma correspondiente a las impregnaciones blancas, mostrando presencia de portlandita. calcita, bxido de calcio y feldespato. 
$\mathrm{CaO}$ y $\mathrm{K}_{2} \mathrm{O}$ del agregado. La hermatita e ilmenita también aparecenen la norma, lo que es indicativo del enriquecimiento en fierro y contenido en titanio (Tabla 3).

Los análisis cuantitativos a la microsonda electrónica de la fase vítrea y de la fase metálica de la pseudofulgurita corroboran los datos proporcionados por la fluorescencia de rayos $\mathrm{X}$ y permiten profundizar éstos. En efecto, se observan cristales fracturados de aleaciones de fierro-silicio

\begin{tabular}{|c|c|c|}
\hline CONSITUYYENTE & COMPOSICION & * EN LA Muestra \\
\hline PARTE VITREA & \multirow[b]{2}{*}{ 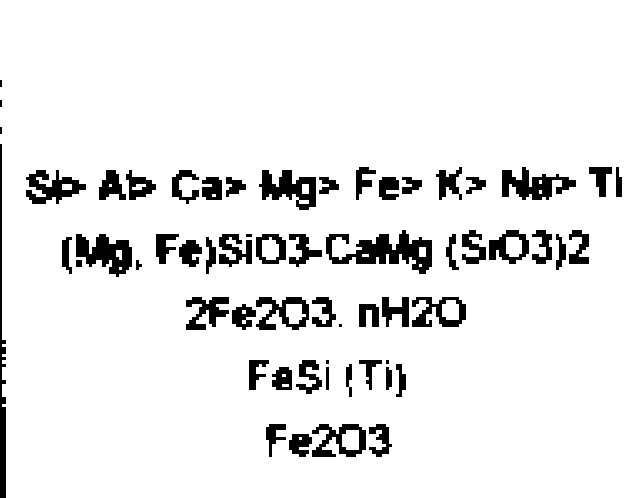 } & \multirow[b]{2}{*}{$\begin{array}{c}87 \\
2 \\
0.5 \\
2 \\
0.5\end{array}$} \\
\hline 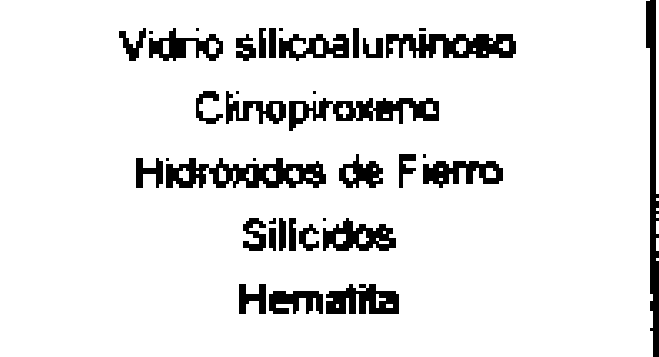 & & \\
\hline PARTE ESCOFACEA & \multirow[b]{2}{*}{$\begin{array}{c}\mathrm{SiO2} \\
\mathrm{SiO2} \\
\mathrm{SiO2} \\
\text { (Ca, NA)ARSSI2OB }\end{array}$} & \multirow[b]{2}{*}{$\begin{array}{l}1 \\
2 \\
2 \\
?\end{array}$} \\
\hline 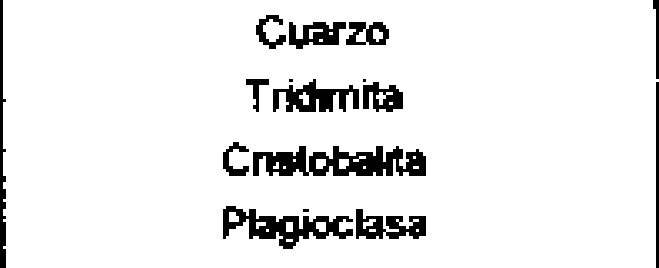 & & \\
\hline AMEOAMCKONES BUACAS & \multirow[b]{2}{*}{$\begin{array}{c}\mathrm{CaCO3} \\
\mathrm{Ca}(\mathrm{OH}) \mathbf{2} \\
\mathrm{CaO} \\
\text { NaAIST3OB-CaAl2SIOB }\end{array}$} & \multirow[b]{2}{*}{$\begin{array}{l}0.5 \\
0.5 \\
0.5 \\
0.5\end{array}$} \\
\hline $\begin{array}{l}\text { Cakitita } \\
\text { Portlandika } \\
\text { Oxido de calcio } \\
\text { Feldespatos }\end{array}$ & & \\
\hline & TOTAL & 100 \\
\hline
\end{tabular}

Tabla 1. Composición mineralígica y porcentaje modal de la parte vitrea, escoriácea e impregnaciones blancas de la pseudofulgurita El Rosario.

\begin{tabular}{|c|c|c|c|c|c|}
\hline 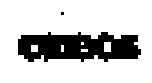 & $=x+4$ & $=0$ & גומוזהת & manom & mang \\
\hline 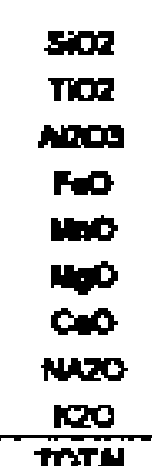 & 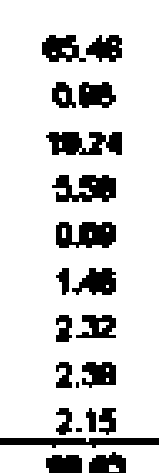 & 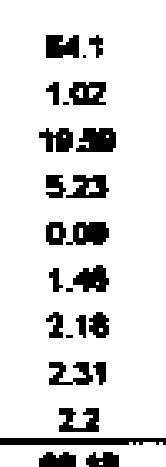 & 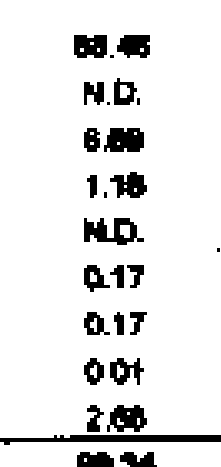 & $\begin{array}{l}91.19 \\
02 \\
02.3 \\
10 \\
10 \\
12 \\
12 \\
18 \\
\text { is } \\
2.4 \\
194\end{array}$ & $\begin{array}{l}0 . \\
0 \\
0 \\
02 \\
0 \\
0 \\
0 \\
0 \\
0\end{array}$ \\
\hline & & 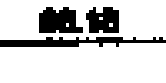 & & & \\
\hline
\end{tabular}

Tabla 2. Análisis quimicos de roca fotal (en \% en peso) de la parte vitrea (MET-LA) y escoriacea (MET-1B) de la pseudofulgurita El Rosario. A título de comparación la compasición quimica de una fulgurita de Australia (Frondel. 1962) $y$ de fulguritas de Michigan (Essene y Fisher, 1986). (silícidos), conteniendoexsoluciones lamelaresy verniformes de similar composición (Fig. 8). Estas exsoluciones presentan variaciones significativas en sus contenidos en $\mathrm{Fe}$ y $\mathrm{Si}$ del borde hacia el centro, con relaciones de $2: 1$ a $1: 1$ y trazas de Ti (Tabla 4). Tambièn se observan glóbulos metálicos de silícidos enriquecidos en $\mathrm{Fe}-\mathrm{T}_{1}$ y de tamaño pequeño $(<5$ $\mathrm{mm}$ ) embestidos en vidrio con contenidos en $\mathrm{SiO}_{2}$ variando entre61-65\%(Fig. 9).

\section{CLASIFICACIÓN Y ORIGEN DEL AGREGADO}

De acuerdo con la literatura geológica, las rocas vítreas se forman por enfriamiento súbito o por choque que induce destrucción de la estructura cristalina. De acuerdo a $O$ 'Keef (1984), los vidrios de origen natural son de varios tipos, a saber: volcánico, de impacto, diapléctico, tectita, fulgurita y combustion-metamórfico. El origen de estos vidrios es resumido en la Tabla 5. Los tres primeros tipos de vidrio han sido

\begin{tabular}{|c|c|c|}
\hline Minzenes nopanativos & MET-1A & mat-iB \\
\hline 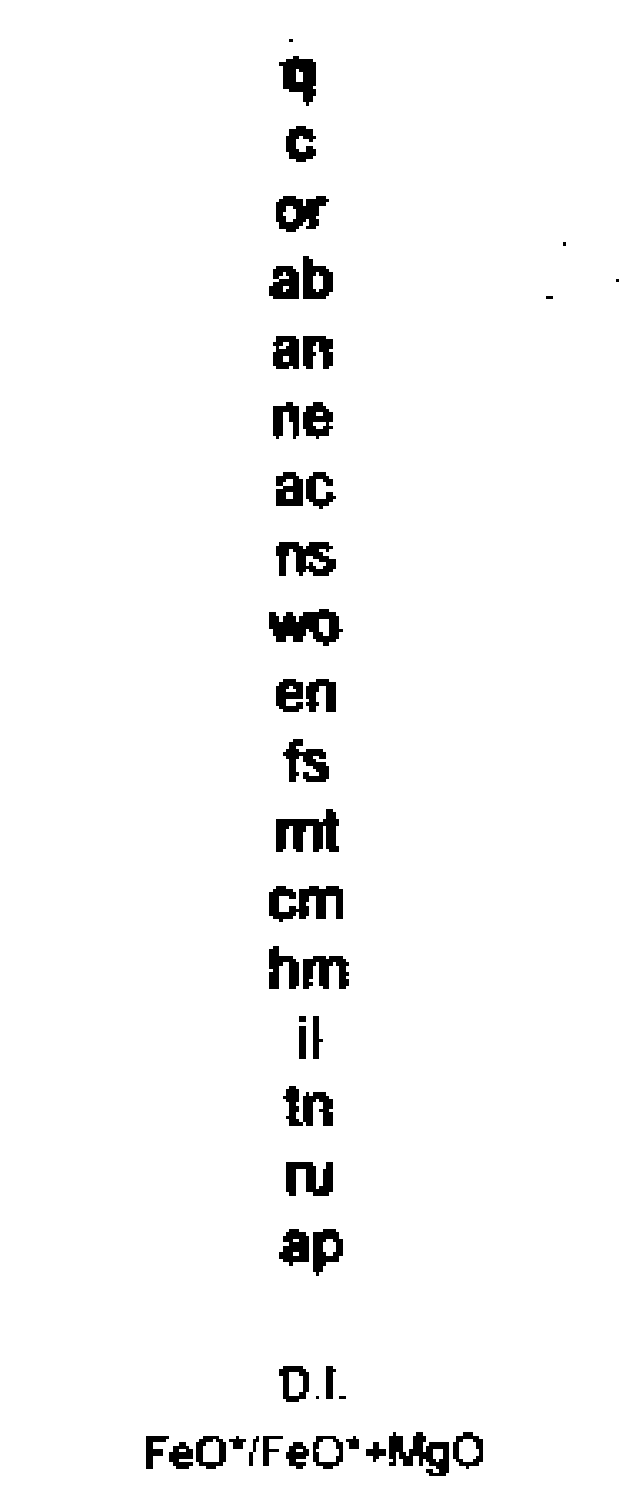 & $\begin{array}{c}30.22 \\
8.79 \\
127 \\
20.21 \\
11.44 \\
- \\
- \\
- \\
- \\
3.63 \\
- \\
- \\
0.04 \\
4.85 \\
1.06 \\
- \\
0.09 \\
\cdot \\
69 \\
0.79\end{array}$ & $\begin{array}{c}35.44 \\
9.47 \\
12.99 \\
19.54 \\
10.75 \\
- \\
\vdots \\
- \\
- \\
3.63 \\
- \\
- \\
0.06 \\
5.02 \\
0.6 \\
- \\
0.71 \\
- \\
08 \\
0.78\end{array}$ \\
\hline
\end{tabular}

Tabla 3. Norma CIPW de la parte vitrea (MET-LA) y escoriácea (MET-IB) de la pseudofulgurita El Rosario.

D.I.=Índice de diferenciación. 
encontrados tanto en la superficie de la Tierra, como también en la Luna y algunos meteoritos, mientras que los tres restantes están restringidos a cuerpos planetarios con atmósfera.

Las evidencias encontradas en el terreno de cultivo, tales como la presencia de una cavidad de forma ovalada, una línea de alta tensión rota, fragmentos vítreos y escoriáceos

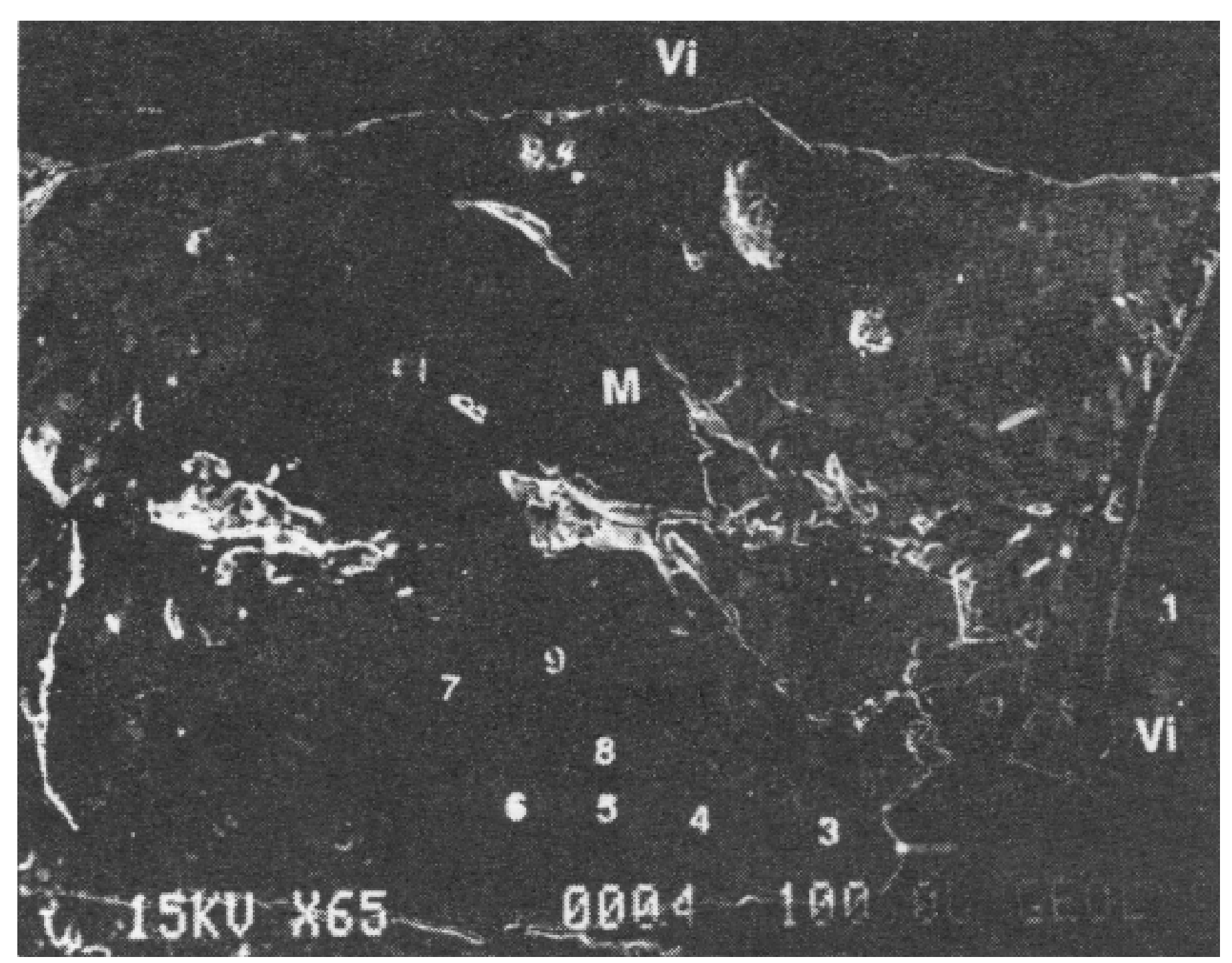

Figura 8. Fotomicrografia obtenida a la microsonda electrónica mostrando una esfera metálica de silicido (M) incluida en vidrio silicico (Vi). Se observan exsoluciones lamelares y vermiculares de Fe-Si y el fracturamiento característico de los cristales. Los números indican la localización de los análisis puntuales.

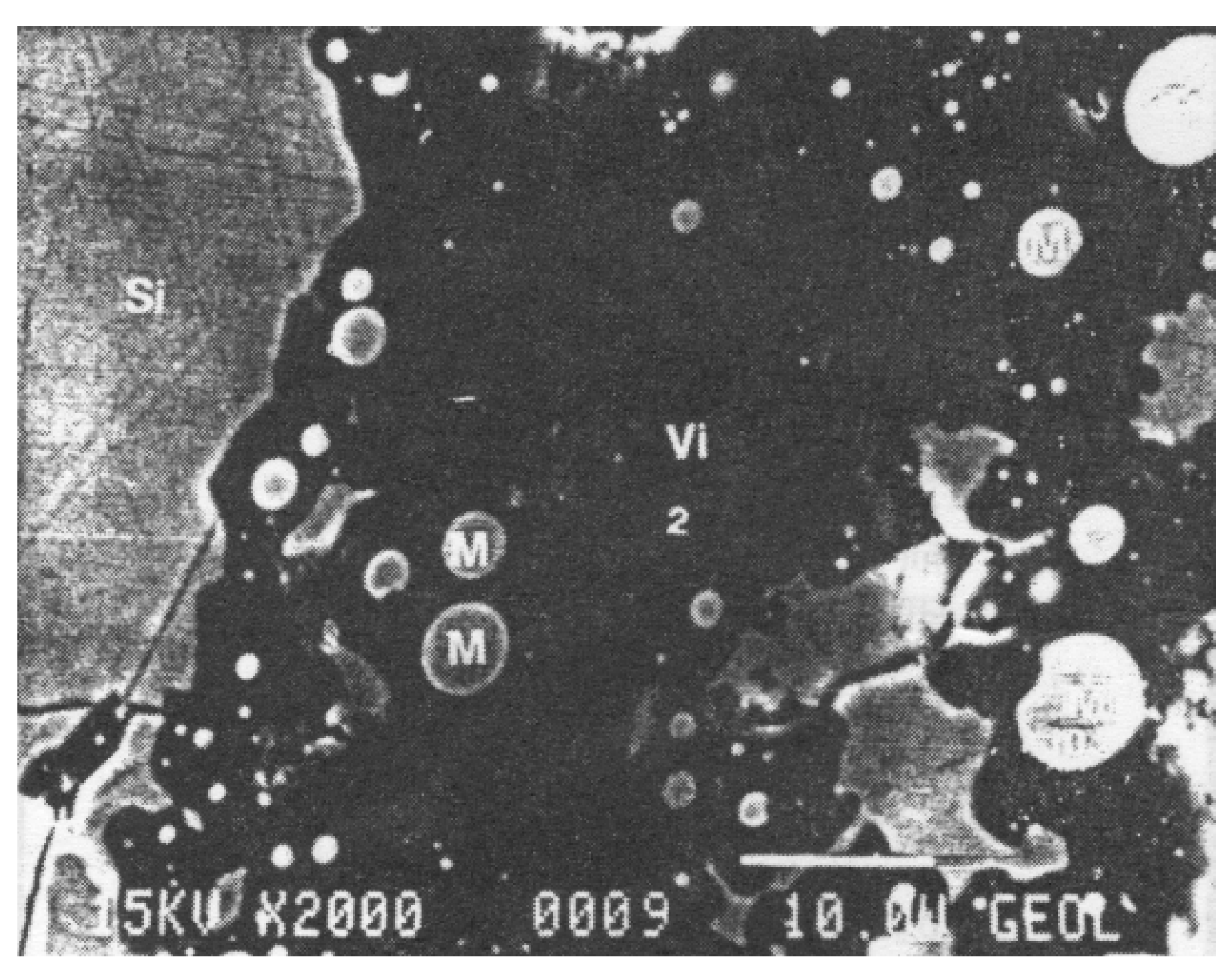

Figura 9. Fotomicrograjia obieniau u ıи mucrusunaa electronica mostrando glóbulos de silícidos (M) de tamaño pequeño incluidos en vidrio silicico (Vi). A la izquierda un cristal de silicido (Si) con estrias de pulido. Los números indican la localización de los análisis puntuales. de composición similar al fragmento mayor, así como las características megascópicas, microscópicas y la composición mineralógica y química del agregado vítreo, son compatibles con las de las fulguritas (Feldman, 1987), los productos terrestres resultantes de rayos impactando la superficie del suelo o rocas. Las fulguritas han sido producidas también artificialmente haciendo pasar una corriente eléctrica a través de arena $\mathrm{u}$ otro material, o cuando líneas de alta tensión han sido rotas sobre suelo arenoso. A estos últimos productos se les denomina pseudofulgurita, ya que no fue formada por fusión producida por el efecto de un rayo sino de una simple descarga eléctrica inducida por la ruptura de una línea de alta tensión (13,000 volts de tensión de aceleración; técnicos de la CFE, comunicación oral) impactando la superficie del terreno arcillosoy limoso. Según elDictionary of Geology (Tomkeieff, 1983), las fulguritas (del latín fulgur igual a fundido) son tubos vitrificados de material silíceo fundido producido cuando un rayo impacta la superficie del terreno. Los vidrios son de color blanco grisáceo, café, marrón, oscuro, negro o verdes amarillentos, bulbosos o con protuberancias alargadas, a veces bifurcadas. Su superficie exterior es rugosa con excrescencias en forma de hilo y vesicular. Algunas de ellas libres de oquedades son parecidas megascópicamente a obsidiana negra, aunque la gran

\begin{tabular}{|c|c|c|}
\hline OXIDOS & 1 & 2 \\
\hline SiO2 & 61.63 & 65.05 \\
Ti122 & 0.47 & 0.25 \\
A1203 & 23.7 & 22.35 \\
FeO & 2.91 & 1.73 \\
MnO & 0.07 & 0.05 \\
MgO & 3.78 & 3.66 \\
CaO & 5.87 & 5.29 \\
NA2O & 0.75 & 0.69 \\
K20 & 0.83 & 0.92 \\
P2O5 & 0 & 0 \\
\hline TOTAL & 100 & 100 \\
\hline & & \\
\hline
\end{tabular}

\begin{tabular}{|c|c|c|c|c|c|c|c|c|}
\hline ELEMENTO & 3 & 4 & 5 & 6 & 7 & 6 & 9 & 10 \\
\hline $\begin{array}{l}\mathrm{Si} \\
\mathrm{Fe}\end{array}$ & $\begin{array}{l}34.63 \\
65.1\end{array}$ & $\begin{array}{l}53.69 \\
46.3\end{array}$ & $\begin{array}{l}34.83 \\
65.17\end{array}$ & $\begin{array}{l}54.48 \\
45.52\end{array}$ & $\begin{array}{l}34.82 \\
65.13\end{array}$ & $\begin{array}{l}54.52 \\
45.48\end{array}$ & $\begin{array}{l}54.7 \\
45.3\end{array}$ & $\begin{array}{l}30.84 \\
65.41\end{array}$ \\
\hline$\pi$ & 0.07 & 0.01 & 0 & 0 & 0.05 & 0 & 0 & 3.75 \\
\hline TOTAL & 100 & 100 & 100 & 100 & 100 & 100 & 100 & 100 \\
\hline
\end{tabular}

Tabla 4.- Análisis puntuales a la microsonda electrónica de la fase vitrea y de la fase metálica de la pseudofulgurita expresados en porcentaje en peso. 1 y 2 fase vitrea. 3 a 10 fase metálica. La ubicación de los análisis efectuados se indican en las figuras 8 y9. 
mayoría presentan tubos pequeños de vidrio pasando al interior de la roca. Estas rocas son comunes en arenas de tuna del desierto o en planicies costeras. Ellas han sido ieportadas por Frondel (1962) como vidrios naturales o artificales de composición silícica ( $90-99 \%$ de $\mathrm{SiO}_{2}$ ), formadas cuando un rayo golpea y mezcla arenas cuarcíferas, rocas o suelo. Un contenido en ślice variando de 85 al $99 \%$ ha sido reportado para fulguritas por Essene y Fisher (1986). Debe considerarse, sin embargo, que la composición química global de las fulguritas depende del protolito o del material a partir del cual se formaron estos agregados vítreos.

El impacto de rayos sobre el terreno produce varios efectos inusuales ocasionando cambios abruptos en la presión, temperatura, densidad y velocidad del medio impactado, provocando mezcla, vaporización, fundido y transformación mineralógica o en su defecto fuertes deformaciones de los materiales rocosos (Brook et al., 1962; Hill, 1971; Uman y Knider, 1989; Newcott, 1963). La fulgurita resultante típicamente consiste de vidrio producido por el intenso calor inducido por la descarga eléctrica. Estas rocas son generalmente tubulares, con interior hueco y frágil y exterior poroso (Daly et al., 1993). Las fulguritas contienen fases que requieren altas temperaturas, excediendo en general $1000^{\circ} \mathrm{C}$, siendo la temperatura de mezcla antes de la formación del vidrio estimada entre 1900 a $2700^{\circ} \mathrm{C}$ (Essene y Fisher, 1986), reflejando las condiciones extremas producidas localmente por el rayo. Esto se produce cuando la descarga eléctrica causa que el campo eléctrico rebase el límite de rompimiento del aire adyacente produciendo mezcla y vaporización. Este rompimiento causa una descarga convectiva formada partir del objeto impactado hacia arriba. La energía liberada y los voltajes y temperaturas involucradas son verdaderamente extraordinarias para alcanzar la mezcla de materiales.

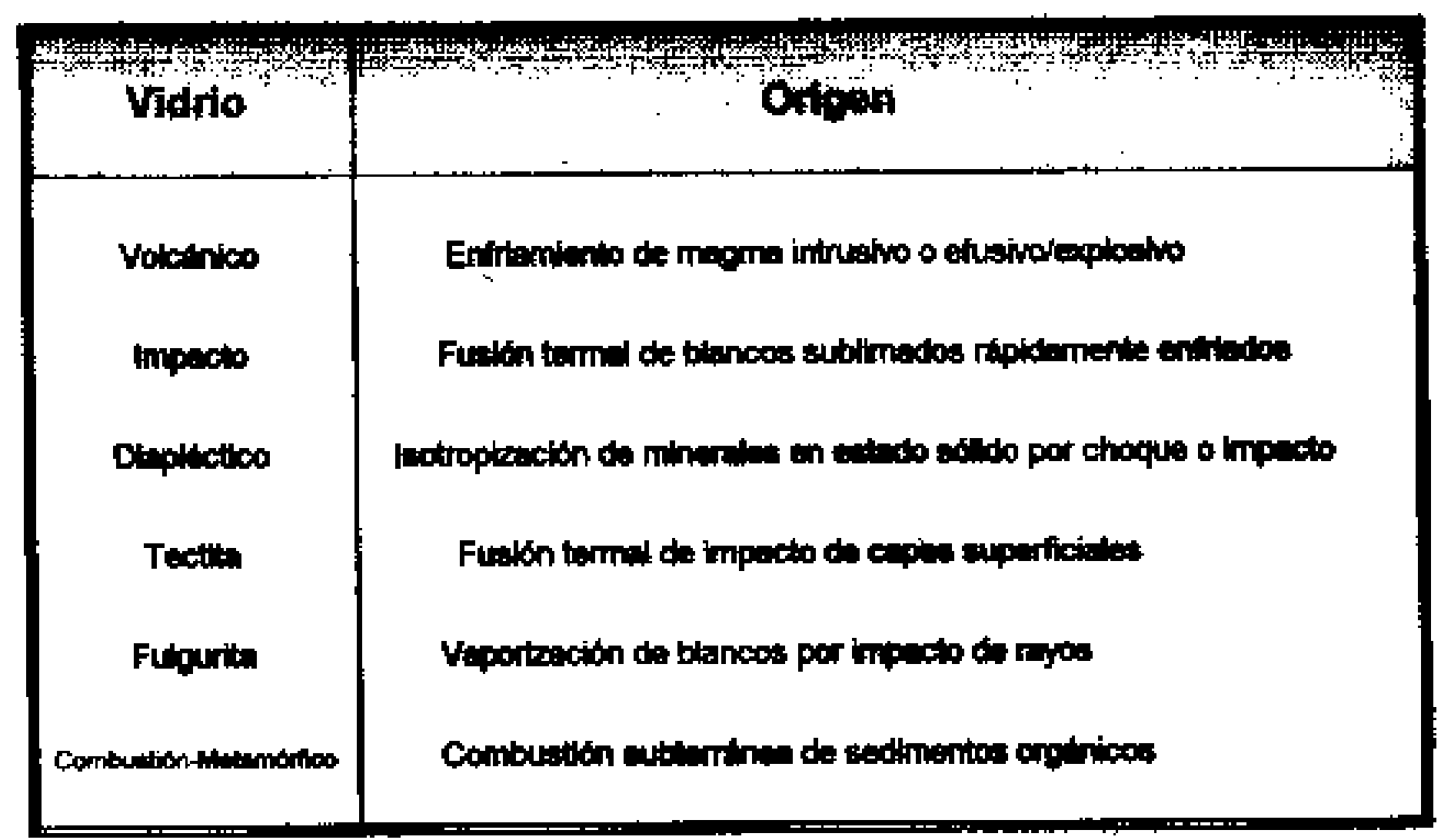

Tabla 5. Tipos de vidrios de origen natural (segin O'Keefe, 1984).
Los minerales encontrados en las fulguritas son polimorfos de la sílice, rara vez $\mathrm{ZrO}_{2}$, mulita $\left(\mathrm{Si}_{2} \mathrm{Al}_{6} \mathrm{O}_{13}\right)$ (Frondel, 1962) y recientemente se ha señalado la presencia de grafito, fullerenos $\left(\mathrm{C}_{50}\right.$ y $_{70}$; Daly et al., 1993), silícidos $\left(\mathrm{Fe}_{\mathrm{x}} \mathrm{Si}_{\mathrm{i}-\mathrm{x}}\right.$ ), compuestos de fierro, titanio y fósfidos (Essene $\mathrm{y}$ Fisher, 1986), todos ellos formados a altas temperaturas y bajas presiones.

En rocas terrestres, la presencia de tridimitay cristobalita es común en las cavidades de rocas volcánicas vítreas. Estos minerales se supone se formaron tardiamente por emanaciones de gases calientes actuando sobre la roca aún no del todo solidificada. Según Deer et al. (1993), la tridimita se forma arriba de los $870^{\circ} \mathrm{C}$ y cuando esta se calienta a $\pm 1470^{\circ}$ C se transforma en cristobalita. La presencia de estos polimorfos sugiere altas temperaturas alcanzadas por la pseudofulgurita El Rosario. Esta temperatura alta es también sugerida por la presencia de clinopiroxeno, ya que piroxenos del tipo clinoestatita coexisten con cristobalita a temperaturas de alrededor de $1570^{\circ} \mathrm{C}$ (Mysen, 1988) y se sabe también que para que la arena se convierta en un vidrio se necesita una temperatura de alrededor de $1370^{\circ} \mathrm{C}$. Por otra parte, se sabe que una descarga de 28000 volts de tensión de aceleración afectando un terreno blando y conductor de electricidad, puede producir una temperatura de aproximadamente
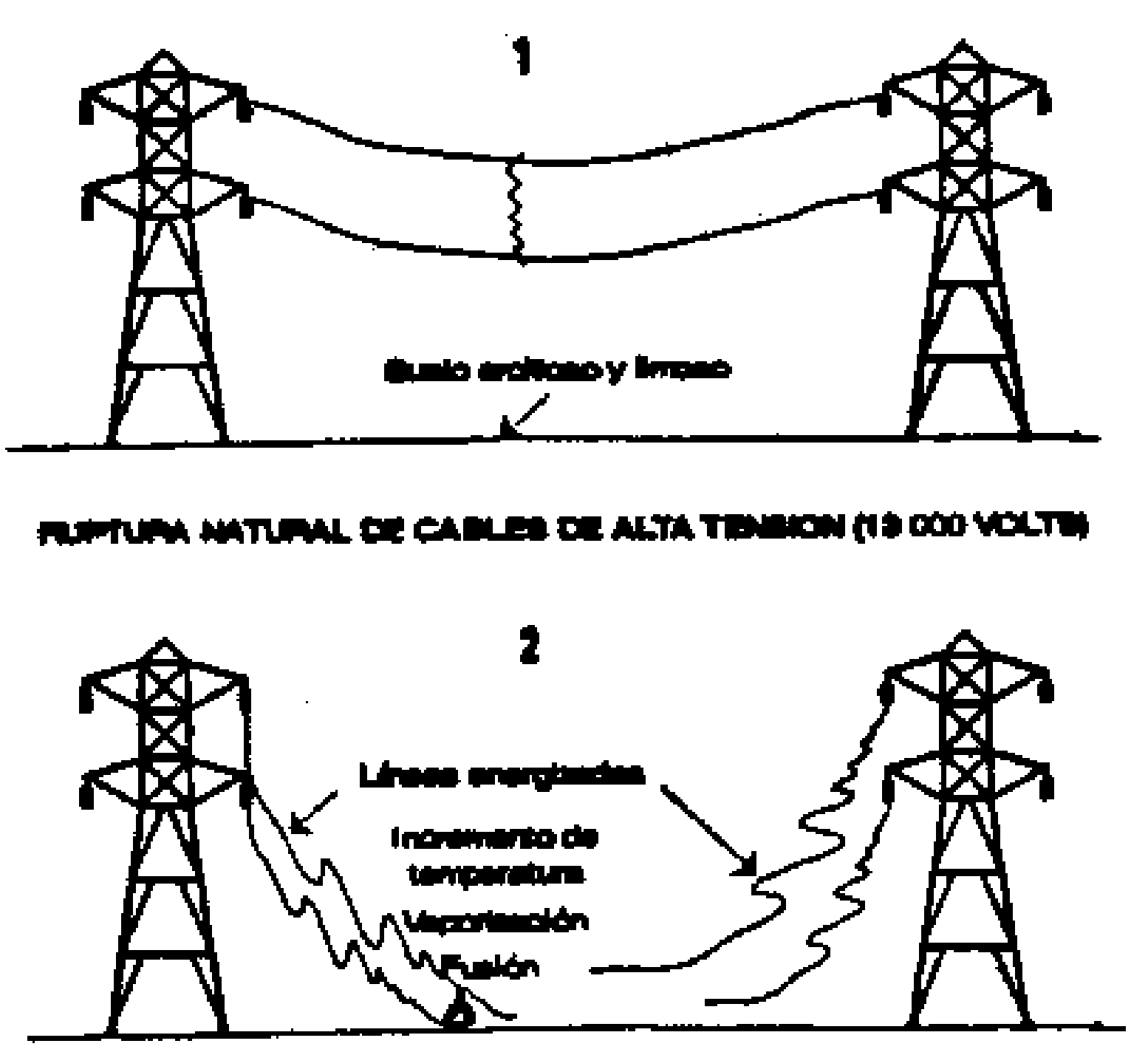

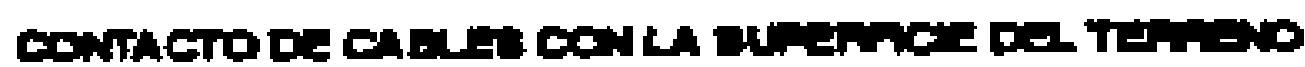

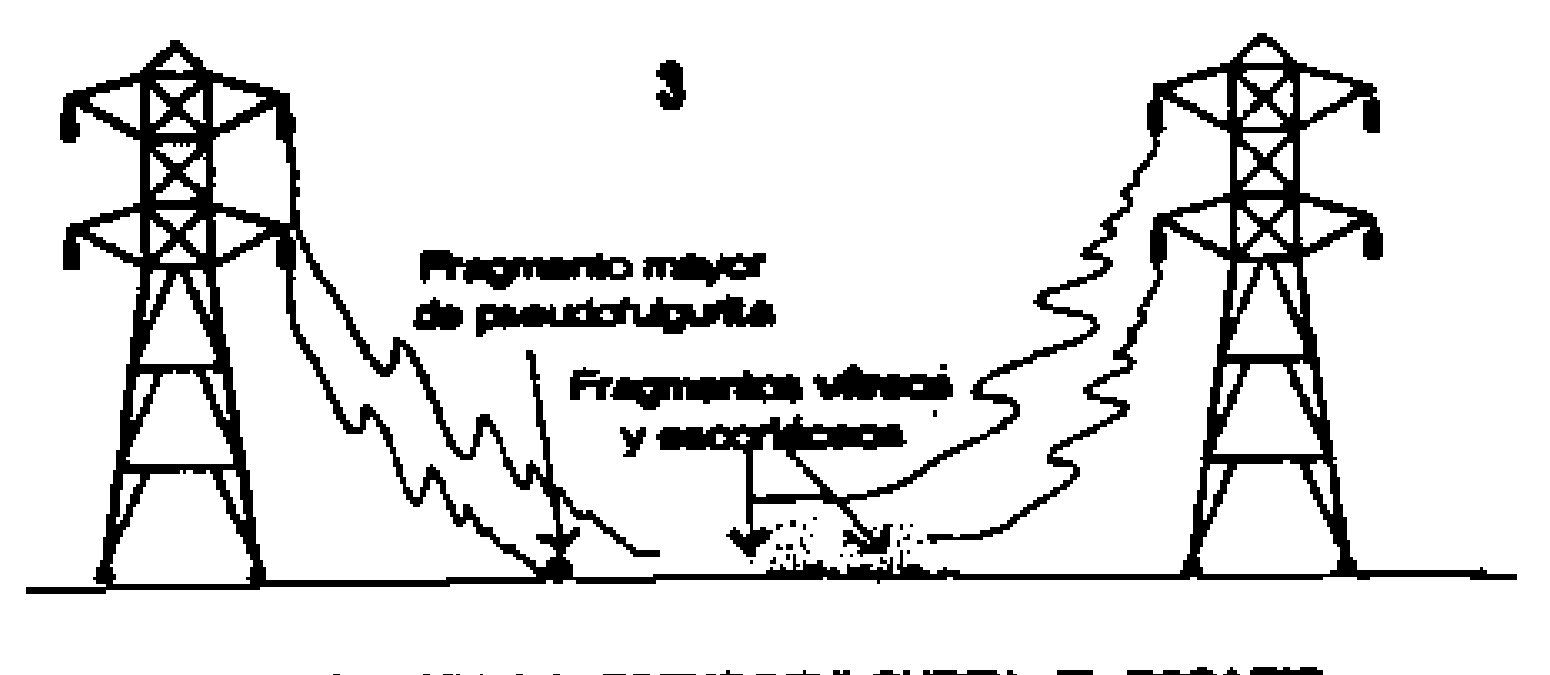

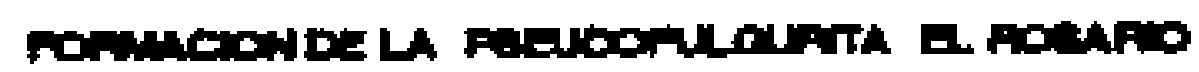

Figura 10. Origen de la pseudofulgurita El Rosario. 
$2500^{\circ} \mathrm{C}$ (técnicos de la CFE, comunicación oral), lo cual es suficiente para fundir localmente el terreno y producir vaporización.

El hervimiento del agregado vitreo está evidenciado por la abundancia de vesiculas y los canales que intercomunican éstas. La vaporización del oxigeno durante el hervimiento proporcionó las condiciones idóneas para el desarrollo de los silícidos.

Estos silícidos, que consisten de tetraedros de sílice ocupados por otros elementos tales como $\mathrm{Fe}, \mathrm{Al}, \mathrm{Ti}, \mathrm{B}, \mathrm{P}, \mathrm{Sn}$ y otros (Feldman, 1987), han sido encontrados en fulguritas que han experimentado una extrema reducción y denotan una inmiscibilidad entre fase vitrea y metálica (Essene y Fisher, 1986). Estas condiciones son sugeridas también por las exsoluciones de plagioclasa y tridimita en la parte vitrea que dan evidencia de inmiscibilidad y también por la forma esferoidal de las esferas metálicas o glóbulos que sugieren desmezcla de líquido metálico a partir de un líquido silicatado (Essene y Fisher, 1986).

Lacomposición químicapredominante en sílice y alúmina de la pseudofulgurita es un reflejo del material original a partir del cual ésta se formó, que son suelos del tipo Vertisoles pélicos y Feozens con propiedades vérticas con contenidos en arcilla superiores al $35 \%$, contenidos variables en carbonatos $(0.5-8 \%)$ y bajos en materia orgánica (Detenal, 1982). Este tipo de suelo presenta una composición predominante de arcillas del tipo de la montmoritlonita $\left(\mathrm{Al}_{\mathbf{1 . 6 7}} \mathrm{Mg}_{0.33}\right.$ $\left.(\mathrm{OH})_{2}\left(\mathrm{Si}_{4} \mathrm{O}_{10}\right)_{0.33} \mathrm{Na}_{0.33}\left(\mathrm{H}_{2} \mathrm{O}\right)_{4}\right)$. También se sabe que la composición de las líneas de alta tensión es aluminio, acero, plástico y partes cerámicas. Estos materiales pudieron fundirse con el suelo para dar origen a un agregado vítreo sílicoaluminoso con predominio de materiales refractarios.

\section{CONCLUSIONES}

La pseudofulgurita El Rosario constituye un fragmento vítreo exótico en el estado de Hidalgo. Sus caracteristicas sugieren que se formó por mezcla producida por la descarga eléctrica de una línea de alta tensión (13000 volts de tensión de aceleración) con la superficie del terreno de cultivo arcilloso-limoso que indujo vaporización, fundido, transformación mineralógica y solidificación del material impactado. Su peso específico es 2.548 . El vidrio refractario que la constituye es de composición sílicoaluminosa con $n>1.537$ conteniendo escasas diseminaciones de clinopiroxeno, asi como esferas y glóbulos de silícidos con trazas de titanio. En su parte escoriácea se identificaron polimortos de la silice (cuarzo, tridimita y cristobalita) y plagioclasa. La parte vitrea y escoriácea están constituidas esencialmente de refractarios que expresan químicamente su abundancia en $\mathrm{SiO}_{2}$,
$\mathrm{Al}_{2} \mathrm{O}, \mathrm{y} \mathrm{FeO}^{*}$, y contenidos bajos en $\mathrm{Na}_{2} \mathrm{O}, \mathrm{CaO}, \mathrm{K}_{2} \mathrm{O}$ y TiO Las impregnaciones blancas formadas de calcita, óxido de calcio, portlandita y feldespatos, sugiere adición de calcio posiblemente suministrado por las raices de la vegetación existente en el terreno de cultivo o por la carbonatación de las tobas del cual procede el suelo arcilloso y limoso implicado. Se sabe, en efecto, que los productos formados por la silicificación de raíces de plantas están compuestos de carbonato de calcio, limonita y calcedonia (Frondel, 1962).

Las características similares de la pseudofulgurita y de los fragmentos vítreos y escoriáceos pequeños encontrados en el terreno de cultivo sugieren que estos son fragmentos disgregados del agregado mayor o que ellos fueron formados por el mismo fenómeno que produjo éste

La pseudofulgurita El Rosario daría evidencia de un origen exótico, aunque terrestre, ya que es completamente ajena a las formaciones geológicas adyacentes y fue formada por procesos poco usuales en la naturaleza (Fig. 10).

\section{AGRADECRMIENTOS}

Los autores manifiestan su agradecimiento a las autoridades del Consejo de Recursos Minerales por las facilidades otorgadas para la publicación del presente trabajo. Se agradece asimismo al personal del Centro Experimental Tecamachalco, Ings. Ma. de la Luz Rivas, Alfonso Cruz y Rolando Nieto por el análisis de las muestras, así como también a los Ings. Gregorio Medina García y José Cárdenas Vargas, por su apoyo logístico. Se agradece asimismo a la Bióloga Margarita Reyes Salas del Instituto de Geología de la UNAM por su apoyo en los análisis cuantitativos de la fase metálica y vitrea en la microsonda electrónica.

\section{BIBLIOGRAFIA}

DETENAL, 1982, Sintesis Geográfica del Estado de Hidalgo: México, D.F., Secretaría de Programación y Presupuesto, Dirección de Estudios del Territorio Nacional, $134 \mathrm{p}$.

Brook,M.,Kitagawa, N.\& Warkman, E.I., 1962, Quantitative study of strokes and continuing currents in lighting discharges to ground. Joumal of Geophysical Research, v. 67, No. 2,p. 649-659.

Daly, T.K., Buseck, P.R., Williams, P. \& Lewis, C.F., 1993, Fullerenes from a fulgurite. Science, v. 259, p. 1599-1601.

Deer, W.A., Howie, R.A. and Zussman, J., 1993, An introduction to the rock-forming minerals. Longman Scientific \& Technical, 2nd edition, $696 \mathrm{p}$.

Essene, E.K. \& Fisher, D.C., 1986, Lightning-strike fusion: Extreme reduction and metal-silicate liquid inmiscibility. Science, v. 236, p. 189-193. 
Feldman, V., 1987, Comparative characteristics of impactite, tektite and fulgurite glasses. In Second Intemational Conference on Natural Glasses. Prague, 21 -25 september 1987, published by Charles Universitha, Praga, Kanta, J., ed., 435 p.

Frondel, C., 1962, Silicaminerals, vol 3 Dana's System of Mineralogy, p. 318-329, John Wiley \& Sons, New York.

Hill, R.D., 1971, Channel heating in return-stroke lightning. Joumal of Geophysical Research, v. 76, No. 3,p. 637-645.

Mysen, B.O., 1988, Structure and properties of silicate melts Developments in Geochemistry 4, Elsevier, Amsterdam, Oxford, New York, Toronto, $354 \mathrm{p}$.
Newcott, W.R., 1993, Lightning. Nature's high-voltage spectacle. National Geographic, v. 184, No. 1, p. 82-103.

O' Keef, J.A., 1984, Natural glasses. In Natural Glasses, edited by Pye, L.D., O'Keef, J.A. \& Fréchette, V.D., North Holland, Amsterdam, p. 1-17.

Tomkeieff, S.I., 1983, Dictionary of Petrology. Edited by Walton, E.K., Randall,B.A.O.,Battey,M.H. \& Tomkeief, O., John Wiley \& Sons Ltd. Chichester, New York, Brisbone, Toronto, Singapore, $680 \mathrm{p}$.

Uman, M.A. \& Knider, Ph., E., 1989, Natural and artificially initiated lightning. Science, v. 246, No. 4929, p. 457-463. 